\title{
ALCOHOL-RELATED PROBLEMS AND HIGH RISK SEXUAL BEHAVIOUR IN PATIENTS WITH HIV/AIDS ATTENDING MEDICAL CLINIC IN A NIGERIAN UNIVERSITY TEACHING HOSPITAL
}

\author{
V. O. Olisah O. Adekeye T. L. Sheikh A. J. Yusuf \\ Department of Psychiatry, A.B.U.T.H, Zaria, Nigeria
}

\begin{abstract}
This study was designed to determine the rate of alcohol related-problems in patients with HIV/ AIDS and its association with high risk sexual behavior. A consecutive sample of 120 patients with HIV/AIDS attending the Medical Out-patient Department (M.O.P.D) in Ahmadu Bello University Teaching Hospital (A.B.U.T.H), Zaria was assessed. All participants were screened for alcohol related problems using the Alcohol Use Disorder Identification Test (AUDIT). High risk sexual behavior was assessed using the HIV Risk-taking Behavior Questionnaire (HRBQ). Alcohol-related problems were found in $28.3 \%$ of participants $(10 \%$ had hazardous use, $3.3 \%$ had harmful use and $15 \%$ had alcohol dependence). There was a significant association between alcohol-related problems and risky sexual behavior. Alcohol-related problems are fairly common in people already infected with HIV/AIDS and are associated with high-risk sexual behavior. Thus, screening and treatment should be part of an effective HIV intervention program.
\end{abstract}

KEY Words: Alcohol related problems, high-risk sexual behavior, hazardous use, harmful use, alcohol dependence

\section{INTRODUCTION}

People with alcohol use disorders are more likely than the general population to contract HIV. Similarly, rates of alcohol problems are high among HIV/AIDS patients (Petry, 1999). Lifetime prevalence rates of alcohol use disorders ranging from $29 \%$ to $60 \%$ have been found among HIV positive populations (Bryant, 1998). This is 2 to 4 times higher than in the general population. Alcohol use is associated with high-risk sexual behaviors and intravenous drug use which are two major modes of HIV transmission.
In persons already infected, the combination of heavy drinking and HIV has been associated with increased medical and psychiatric complications, delays in seeking treatment (Samet et al., 1998), difficulties with HIV medication adherence (Cook et al., 2001; Wagner et al., 2001), and poorer HIV treatment outcomes (Lucas et al., 2002). Decreasing alcohol use in people who have HIV or who are at risk for becoming infected reduces the spread of HIV and the diseases associated with it.

Nigeria has the third largest population of people living with HIV/AIDS in the world,

Correspondence to: Dr. Victor Obiajulu Olisah, Department of Psychiatry, Ahmadu Bello University Teaching Hospital, Zaria. P.M.B 06, Zaria, Kaduna state, Nigeria. E-mail address: olisahvictor@yahoo.com, Phone no. +23408037018902 
after India and South Africa. The seroprevalence rate has been on the increase from $1.8 \%$ in 1991 to $5.4 \%$ in 1999 with a modest drop to $4.4 \%$ in 2005 (Federal Ministry of Health sentinel survey report, 1999 and 2005).

Alcohol-related problem is a major public health issue. A review of the studies on alcohol use in Nigeria shows that there has been a rapid increase in alcohol availability and consumption in recent times with young adults in universities and colleges being those mainly concerned (Abiodun, 1991). Most alcohol-related problems appear in non-alcoholic dependent individuals who fall into the categories of hazardous or harmful drinkers according to the WHO (2000) terminology.

Studies in Nigeria have focused on lifetime and current prevalence rates of alcohol use without exploring alcohol-related problems (Odejide et al., 1987; Adelekan et al., 1992). Adewuya (2005) in a sample of University students found Alcohol related problems in 13.2\% of subjects of which $9.4 \%$ had Hazardous drinking, 3.1\% had Alcohol abuse and 0.74\% had Alcohol dependence. There is an urgent need to encourage extensive epidemiological and longitudinal studies of alcohol-related problems in Nigeria in order to accurately determine the populations at risk. Early detection of people with hazardous alcohol intake and time bound interventions aimed at decreasing alcohol consumption and thus the likelihood of harm and dependence is warranted.

People who abuse alcohol are more likely to engage in behaviors that place them at risk for contracting or transmitting HIV. A history of heavy alcohol use has been correlated with a lifetime tendency toward high-risk sexual behaviors, including multiple sex partners, unprotected intercourse, sex with high-risk partners (e.g., injection drug users, prostitutes), and the exchange of sex for money or drugs (Windle, 1997; Avins et al., 1994; Boscarino et al., 1995; Malow et al., 2001). There may be many reasons for this association. For example, alcohol can act directly on the brain to reduce inhibitions and diminish risk perception (MacDonald et al., 2000; Fromme et al., 1999; Cooper, 2002). Decreasing alcohol use among
HIV patients not only reduces the medical and psychiatric consequences associated with alcohol consumption but also decreases other drug use and risky sexual behavior and hence reduces HIV transmission (Lucas et al., 2002). Thus, alcohol and other drug abuse treatment can be considered primary HIV prevention as well (Metzger et al., 1998).

This study is the first of its kind in northern Nigeria and the rational for the study is based on the fact that clinicians in the care of patients with HIV/AIDS in A.B.U.T.H, Zaria observed the persistence of high risk sexual behavior in some patients despite adequate counseling about the various modes of HIV transmission and prevention. Our objective was to determine the rate of alcohol related-problems in these patients with HIV/AIDS and to test its association with high risk sexual behavior. This will help create awareness among clinicians and other healthcare professionals involved in the care of people living with HIV/AIDS about alcohol related problems and its association with risky sexual behavior, so as to promote interventions that will enhance routine screening, early diagnosis and treatment of alcohol related problems in this group of patients.

\section{METHOD}

The participants were made up of a consecutive sample of 120 patients with HIV/AIDS attending the virology clinic at the Ahmadu Bello University Teaching Hospital, Zaria during the period from April to May 2008.

The Ethics and research Committee of the University Teaching Hospital approved the study protocol and informed consents were obtained from the participants after the aims and objectives of the study had been explained.

Participants were administered the sociodemographic questionnaire, Alcohol Use Disorder Identification Test (AUDIT) and the HIV Risktaking Behavior Questionnaire (HRBQ). The AUDIT was used to screen for participants with alcohol related problems and those with AUDIT score of 5 to 6 were said to have Hazardous drinking, those with scores of 7 to 8 had Alco- 
hol abuse and those with scores of 9 and above had Alcohol dependence. These cut-off scores were obtained from an AUDIT validation study by Adewuya (2005) in southwest Nigeria where participants' score on the AUDIT questionnaire correlated well with the clinical diagnosis of alcohol related problems using the Composite International Diagnostic Interview (CIDI) with correlation co-efficient of $0.780(p<0.001)$. The study shows that in Nigerian students, an AUDIT cut-off of 5 and above is most appropriate for hazardous alcohol use with sensitivity of 0.935 and specificity of 0.915 . For the diagnosis of harmful use and alcohol dependence, the study recommended cut-offs of 7 and 9 respectively. The recommended cut-off of 5 and above for hazardous alcohol use in Adewuya's is in agreement with the recommended cut-off for the AUDIT in Italy (Piccinelli et al., 1997).

The HRBQ was used to assess participants risky sexual behavior which was categorized as "high" or "low" on the basis of participant reporting the following: having not used a condom at the last sex, having had an occasional partner at the last sex, having had three or more partners in the last 12 months, having had six or more cumulative partners, having a history of sexually transmitted diseases and having received or given money or gift in exchange for the most recent sexual encounter. Respondents reporting fewer than two risk factors were defined as having low risk while those reporting two or more were defined as having high risk sexual behavior (Prata, 2006).

The twelfth edition of Statistical Package for Social Sciences (SPSS-12) Software was used for the data entry and analysis. Chi-square test was used to characterize the significance of the difference between high risk sexual behaviors in HIV/AIDS patients with Alcohol related problems compared to those without Alcohol related problems. The level of significance was set at $5 \%$ confidence limit.

\section{RESULTS}

A total of 120 patients with HIV/AIDS participated in the study. The socio-demographic characteristics of participants are presented in Table 1.

The number of HIV/AIDS patients with and without alcohol related problems are presented in Table 2 below.

High risk sexual behavior was observed in $10(8.3 \%)$ of participants while $110(91.7 \%)$ had low risk sexual behavior.

Risky sexual behavior in HIV/AIDS patients with Alcohol related problems was compared with that in similar group of patients with no Alcohol related problems as shown in table 3.

Table1. Socio-demographic characteristics of participants

\begin{tabular}{|c|c|c|}
\hline Variables & $\mathbf{n}$ & $\%$ \\
\hline \multicolumn{3}{|l|}{ Gender } \\
\hline Male & 78 & 65 \\
\hline Female & 42 & 35 \\
\hline Mean age & 32.4 (SD 6.97) yrs & \\
\hline \multicolumn{3}{|l|}{ Marital status } \\
\hline Single & 54 & 45 \\
\hline Married & 50 & 41.7 \\
\hline Divorced & 6 & 5 \\
\hline Widowed & 10 & 8.3 \\
\hline \multicolumn{3}{|l|}{ Employment } \\
\hline Unemployed & 64 & 53.3 \\
\hline Employed & 56 & 46.7 \\
\hline \multicolumn{3}{|l|}{ Education } \\
\hline Primary & 14 & 11.7 \\
\hline Secondary & 44 & 36.7 \\
\hline Tertiary & 46 & 38.3 \\
\hline Arabic & 6 & 5 \\
\hline None & 10 & 8.3 \\
\hline \multicolumn{3}{|l|}{ Family type } \\
\hline Monogamous & 84 & 70 \\
\hline Polygamous & 36 & 30 \\
\hline \multicolumn{3}{|l|}{ Religion } \\
\hline Christianity & 56 & 46.7 \\
\hline Islam & 64 & 53.3 \\
\hline
\end{tabular}


Table 2. HIV/AIDS patients with and without Alcohol related problems

\begin{tabular}{lcc}
\hline \multicolumn{1}{c}{ Variables } & n & \% \\
\hline Alcohol related problems & 34 & 28.3 \\
No Alcohol related problems & 86 & 71.7
\end{tabular}

\section{Alcohol related problems}

\begin{tabular}{lcc} 
Hazardous use & 12 & 10 \\
Alcohol abuse & 4 & 3.3 \\
Alcohol dependence & 18 & 15 \\
\hline
\end{tabular}

Table 3:.Risky sexual behavior in HIV/ AIDS patients with and without Alcohol related problems

\begin{tabular}{lcc}
\hline \multicolumn{1}{c}{ Diagnosis } & $\begin{array}{c}\text { Low risk sexual } \\
\text { behavior }\end{array}$ & $\begin{array}{c}\text { High risk } \\
\text { sexual } \\
\text { behavior }\end{array}$ \\
\hline $\begin{array}{l}\text { No Alcohol } \\
\text { related problems }\end{array}$ & $84(76.4 \%)$ & $2(20 \%)$ \\
$\begin{array}{l}\text { Alcohol related } \\
\text { problems }\end{array}$ & $26(23.6 \%)$ & $8(80 \%)$ \\
Total & $110(100 \%)$ & 10 \\
& & \\
& $\begin{array}{c}\mathrm{X}^{2}=42.449 \mathrm{df}=1 \mathrm{p} \\
\text { value }<0.05\end{array}$ \\
\hline
\end{tabular}

\section{DISCUSSION}

This study found a preponderance of male gender (65\%) among patients with HIV/ AIDS. This was not surprising considering the fact that the study was conducted in a region where women (especially those belonging to the Moslem faith) has cultural restrictions which tend to limit them from attending the hospital unless when permitted by their husband.

The mean age of the participants was 32.4 (SD 6.97) years. The possible reason for this is that people are most sexually active between the ages of 18 to 25 years and are likely to acquire the infection during this period. However, symptoms may not become apparent until about 10 to 12 years after initial infection making it more likely for patients to present in their 30s. Some previous studies also had similar findings (Cook, 2004).
A large proportion of participants were married $(41.7 \%)$ and about $30 \%$ live in polygamous settings which have major implications and carry the risk of further HIV transmission among spouses and their children. Majority of the participants $(53.3 \%)$ were unemployed. This may be due to ill health and discrimination. Also, unemployed patients may be more likely to indulge in excessive alcohol use as a maladaptive coping strategy.

A significant proportion of the participants had Alcohol related problems (28.3\%), with $10 \%$ having Hazardous use, $3.3 \%$ having alcohol abuse and 15\% alcohol dependence. This is in keeping with several other studies that found increased rate of alcohol related problems in patients with HIV/AIDS (Petry, 1999; Bryant, 1998). The rate of alcohol related problems found in this study is much higher than the $13.2 \%$ found in a sample of University students in Nigeria (Adewuya, 2005). People with HIV/AIDS may be more likely to abuse alcohol as an expression of maladaptive coping strategy or due to the presence of other co-morbid psychiatric conditions which are prevalent in patients with HIV/AIDS such as adjustment disorders, anxiety disorders, personality change and Affective disorders (Yakassai, 2004). It may also be due to chronic frustration from discrimination and unemployment among others. High risk sexual behavior was observed in $8.3 \%$ of participants and $80 \%$ of those with high risk sexual behavior also had alcohol related problems. There was a significant association between alcohol related problems and high risk sexual behavior. This is in agreement with other studies that found a correlation between heavy alcohol use and a lifetime tendency toward high-risk sexual behaviors (Windle, 1997; Avins et al., 1994; Boscarino et al., 1995; Malow et al., 2001).There may be many reasons for this association. Alcohol can act directly on the brain to reduce inhibitions and diminish risk perception and hence produce a tendency towards high risk sexual behavior.

As HIV continues to spreads rapidly in $\mathrm{Ni}$ geria and most of Africa, addressing alcohol use in HIV-infected persons holds potential to 
decrease the transmission of HIV by lowering the prevalence of high-risk sexual behaviors. At present, the most effective way to slow the spread of HIV/AIDS is through changing the sexual risk behaviors that transmit HIV from individual to individual. Drinking alcohol significantly increases the risk of these behaviors in complex ways. The availability and abuse of alcohol increases the difficulty of preventing these sexual risk behaviors. In addition, continued abuse of alcohol by HIV infected individuals increases the negative impact of the disease on the individuals, their families, and the health care system. Interventions to reduce alcohol abuse (such as routine alcohol/drug screening of patients) and treat alcohol dependence in patients already infected with HIV/ AIDS who are vectors for further HIV transmission, will significantly improve the success of HIV preventive and treatment programs.

\section{REFERENCES}

Abiodun, O. A. (1991). Drug abuse and its clinical implications with special reference to Nigeria. Central African Journal of Medicine, 37, 24-30.

Adelekan, M. L., Abiodun, O. A., Obayan, A. O., Oni, G., and Ogunremi, O.O. (1992). Prevalence and pattern of substance use among undergraduates in a Nigerian University. Drug and Alcohol Dependence, 29, 255-261.

Adewuya,A.O. (2005). Validation of the Alcohol Use Disorders Identification Test (Audit) as a screening tool for alcohol-related problems among Nigerian university Students. Alcohol and Alcoholism, 40, 575-577.

Avins, A.L., Woods, W.J., Lindan, C.P., Hudes, E.S., Clark, W., and Hulley, S.B. (1994). HIV infection and risk behaviors among heterosexuals in alcohol treatment programs. Journal of the American Medical Association, 271(7), 515-518.

Boscarino, J.A., Avins, A.L., Woods, W.J., Lindan, C.P., Hudes, E.S., and Clark, W. (1995). Alcohol-related risk factors associated with HIV infection among patients entering alcoholism treatment: Implications for prevention. Journal of Studies on Alcohol, 56(6), 642-653.

Bryant, K. (1998).Alcohol and AIDS: A Guide to Research Issues and Opportunities: National Institute on Alcohol Abuse and Alcoholism.

Cook, J. (2004). Depressive symptoms increase AIDS-related death. American Journal of Public Health, 150 (10), 85-94.

Cook, R.L., Sereika, S.M., Hunt, S.C., Woodward, W.C., Erlen, J.A., and Conigliaro, J. (2001). Problem drinking and medication adherence among patients with HIV infection. Journal of General Internal Medicine, 16(2), 83-88.

Cooper, M.L. (2002). Alcohol use and risky sexual behavior among college students and youth: Evaluating the evidence. Journal of Studies on Alcohol, 14,101-117.

Federal Ministry of Health. (1999). HIV/ Syphilis sentinel seroprevalence survey in Nigeria. Technical report.

Federal Ministry of Health. (2005). HIV/ Syphilis sentinel seroprevalence survey in Nigeria. Technical report.

Fromme, K., D'Amico, E., and Katz, E.C. (1999).Intoxicated sexual risk taking: An expectancy or cognitive impairment explanation? Journal of Studies on Alcohol, 60(1), 54-63.

Lucas, G.M., Gebo, K.A., Chaisson, R.E., and Moore, R.D. (2002). Longitudinal assessment of the effects of drug and alcohol abuse on HIV-1 treatment outcomes in an urban clinic. AIDS, 16(5), 767-774.

MacDonald, T.K., MacDonald, G., Zanna, M.P., and Fong, G.T. (2000).Alcohol, sexual arousal, and intentions to use condoms in young men: Applying alcohol myopia theory to risky sexual behavior. Health Psychology, 19(3), 290-298.

Malow, R.M., Dévieux, J.G., Jennings, T.E., Lucenko, B.A., and Kalichman, S.C. (2001). Substance-abusing adolescents at varying levels of HIV risk: Psychosocial characteristics, drug use, and sexual behavior. Journal of Substance Abuse, 13,103-117. 
Metzger, D.S., Navaline, H., and Woody, G.E. (1998). Drug abuse treatment as HIV prevention. Public Health Reports, 113(1), 97-106.

Odejide, O. A., Ohaeri, J. U., Adelekan, M. L., and Ikuesan, B.A. (1987). Drinking behavior and social change among youths in Nigeria - a study of two cities. Drug and Alcohol Dependence, 30, 227-233.

Petry, N.M. (1999). Alcohol use in HIV patients. International Journal of STD and AIDS, 10(9), 561-570.

Piccinelli, M., Tessari, E., Bortolomasi, M. Piasere O., Semenzin M.,Garzotto N., et al. (1997). Efficacy of the Alcohol Use Disorder Identification Test as a screening tool for hazardous alcohol intake and related disorders in primary care: a validation study. British Medical Journal, 314, 420-424.

Prata, N., Morris, L, Mazive, E., Vahidnia, F., and Stehr, M. (2006). Relationship between HIV risk perception and condom use. International Family planning perspectives, 32 (4).

Samet, J.H., Freedberg, K.A., Stein, M.D., Lewis, R., Savetsky, J., Sullivan, L., et al.
(1998). Trillion virion delay: Time from testing positive for HIV to presentation for primary care. Archives of Internal Medicine, 158(7), 734-740.

Wagner, J.H., Justice, A.C., Chesney, M., Sinclair, G., Weissman, S., and Rodriguez-Barradas, M. (2001). Patient and provider-reported adherence: Toward a clinically useful approach to measuring antiretroviral adherence. Journal of Clinical Epidemiology, 54(1), 91-98.

Windle, M. (1997). The trading of sex for money or drugs, sexually transmitted diseases (STDs), and HIV-related risk behaviors among multi-substance using alcoholic inpatients. Drug and Alcohol Dependence, 49(1), 33-38.

World Health Organisation (2000) International Guide for monitoring Alcohol Consumption and Related harm. Department of Mental Health and Substance Dependence. WHO, Geneva.

Yakassai, B.A. (2004). Neuropsychiatric complications of HIV/AIDS. Annals of African Medicine, 3(2), 63-5. 